\title{
Effects of Aromatherapy of Himekuromoji (Lindera lancea), Essential Oil on Vital and Stress, Emotion and Cognitive Function of the Elderly in Need of Care
}

\author{
Hiroyuki Kikukawa1,2*, Seigo Koura3 ${ }^{3}$, Matsuyo Kuge ${ }^{4}$, Kunioki Miwa ${ }^{5}$, Masayuki Yao5 \\ ${ }^{1}$ Curator, Board of Education of Tamba city, Hyogo, Japan \\ ${ }^{2}$ Graduate School of Landscape Design and Management, University of Hyogo, Japan \\ ${ }^{3}$ Faculty of Rehabilitation Science, Nishikyusyu University, Kanzaki, Japan \\ ${ }^{4}$ Elderly Citizens' Day Service Center Sumire, Tamba, Hyogo, Japan \\ ${ }^{5}$ Kadono Co., Ltd.Tamba, Hyogo, Japan \\ Email: *ag19041@s.okadai.jp
}

How to cite this paper: Kikukawa, H., Koura, S., Kuge, M., Miwa, K. and Yao, M. (2021) Effects of Aromatherapy of Himekuromoji (Lindera lancea), Essential Oil on Vital and Stress, Emotion and Cognitive Function of the Elderly in Need of Care. Open Journal of Therapy and Rehabilitation, 9, 83-97.

https://doi.org/10.4236/ojtr.2021.92007

Received: April 12, 2021

Accepted: May 23, 2021

Published: May 26, 2021

Copyright $\odot 2021$ by author(s) and Scientific Research Publishing Inc. This work is licensed under the Creative Commons Attribution International License (CC BY 4.0).

http://creativecommons.org/licenses/by/4.0/

\begin{abstract}
Although there are limited means of delaying the cognitive decline in patients with dementia, aromatherapy contributes to alleviating the pain manifested through peripheral symptoms and psychological expression of dementia as part of dementia control. However, there are no studies that comprehensively verify the stress reduction effect, cognitive function, vital signs, etc. in the elderly requiring long-term care. In this study, we focused on Himekuromoji (Lindera lancea), which grows naturally in Japan and has no verification cases and decided to verify the possibility of aromatherapy using that essential oil. As a result, olfactory stimulation by Lindera lancea aroma stabilizes the mood and emotions of the client and suppressed the rise in blood pressure. In sentiment analysis, four emotions were quantified using a wearable device. Although the effects of worker emotions on labor productivity have already been elucidated using the same device as in this study, emotional quantification by aromatherapy intervention is unprecedented. There were no significant differences in the four emotions depending on the intervention period and test section, but we were able to capture changes in emotions due to differences in recreational activities. In addition, it is considered that the client was able to spend about $30 \%$ of the activity time in a relaxed manner. It was expected that this aromatherapy as complementary and alternative medicine could contribute to the good emotional control of all the people involved. The COVID 19 pandemic has led to restrictions on human-to-human interaction, so the importance of emotional control represented by stress control is in-
\end{abstract}


creasing for all humankind. Therefore, it was expected that this aromatherapy as complementary and alternative medicine could contribute to the good emotional control of all the people involved.

\section{Keywords}

Pulse, Blood Pressure, Salivary Cortisol, MMSE-J, Day Service Center

\section{Introduction}

According to the World Alzheimer Report 2015, the number of people with dementia worldwide in 2015 was estimated to be 46.8 million. The estimated prevalence was lowest in Central Europe at $4.6 \%$ and highest in North Africa and the Middle East at $8.7 \%$. Compared to 2009, it increased in Asia and Africa and decreased in Europe and North America. Globally, the number of people with dementia is estimated to double every 20 years, increasing to 74.7 million in 2030 and to 131.5 million in 2050 . This data is $12 \%-13 \%$ higher than the 2009 estimate [1].

Against these backgrounds, complementary (alternative) therapies have been used not only for general use but also for the prevention of dementia and have been used for more general health problems in the last 10 years [2]. Complementary therapies include music therapy, animal-assisted therapy, and reminiscence therapy, including aromatherapy [3]. Although there are limited means of delaying the cognitive decline in patients with dementia, aromatherapy contributes to alleviating the pain manifested through peripheral symptoms and psychological expression of dementia as a part of dementia control [4] [5]. In Europe, Australia, and North America, the use of complementary medicine is important and expanding in medicine [6], and aromatherapy is less invasive than other therapies and is nursing in hospitals and hospice. It has become one of the major complementary medicines practiced by teachers and other healthcare professionals [7].

In the first place, aromatherapy is a field of phytotherapy that utilizes the whole plant or a part of the plant for medicinal purposes. The use of essential oils extracted from plants such as fragrant peppermint, sweet marjoram, and rose is aimed at alleviating health problems and improving the overall quality of life [8].

There are various types of essential oils, and it is thought that each has various effects. For example, it has been reported to have a relaxing effect that can promote sleep, relieve pain, and relieve depressive symptoms [2], because essential oils have a calming and stress-relieving effect.

For healthy clients, rosemary and lavender essential oils have been reported to affect cognitive function and mood [9], and reports have found the usefulness of aromatherapy as a non-pharmacotherapy for Alzheimer's patients [3]. However, there are no studies that comprehensively verify the stress reduction effect, cog- 
nitive function, vital signs, etc. in the elderly requiring long-term care. Therefore, in this study, we focused on Himekuromoji (Lindera lancea), which grows naturally in Japan and has no verification cases, and decided to verify the possibility of aromatherapy using the essential oil of Lindera lancea. Specifically, in addition to the evaluation of stress reduction effect, cognitive function, and vital signs, emotion analysis using a wearable device was performed on elderly people requiring long-term care, and the effects were comprehensively verified.

\section{Research Methods}

\subsection{Clients and Intervention Study Schedule}

The clients of the study were selected from among the users requiring nursing care at the A Day Service Center located in Tamba City, Hyogo Prefecture, who had consented to participate in the study and were taking sleeping pills and tranquilizers. In addition, 10 people ( 1 male, 9 females, average age $82.4 \pm 5.6$ years) who could participate in recreational activities in the facility and passed the Lindera lancea Aroma Blend Oil Patch Test. Among the users of the day service center, those who can participate in recreation throughout the test period were selected as the clients of this study (Table 1 ).

In this study, a single-blind, single-case study ( $\mathrm{ABAB}$ design) was adopted, and 10 clients had 2 control periods without aromatherapy intervention and 2 aromatherapy periods with aromatherapy intervention (hereinafter referred to as aromatherapy periods). This was repeated twice a week (Figure 1). A 12-day

Table 1. Basic attributes of clients.

\begin{tabular}{|c|c|c|c|c|c|c|c|}
\hline \multirow{2}{*}{$\begin{array}{c}\text { No. } \\
1\end{array}$} & \multirow{2}{*}{$\begin{array}{c}\text { sex } \\
\text { female }\end{array}$} & \multirow{2}{*}{$\begin{array}{l}\text { age } \\
85\end{array}$} & \multirow{2}{*}{$\begin{array}{c}\begin{array}{c}\text { height } \\
(\mathrm{cm})\end{array} \\
139.0\end{array}$} & \multirow{2}{*}{$\begin{array}{c}\begin{array}{c}\text { weight } \\
(\mathrm{kg})\end{array} \\
47.2\end{array}$} & \multicolumn{2}{|c|}{$\begin{array}{c}\text { daily life } \\
\text { independence level }\end{array}$} & \multirow{2}{*}{$\begin{array}{c}\begin{array}{c}\text { nursing care } \\
\text { level }\end{array} \\
3^{\mathrm{x}}\end{array}$} \\
\hline & & & & & $\mathrm{A} 1^{\mathrm{z}}$ & $\mathrm{IIIa}^{y}$ & \\
\hline 2 & female & 72 & 149.0 & 47.1 & $\mathrm{~A} 1$ & IIa & 2 \\
\hline 3 & female & 73 & 158.0 & 35.6 & B1 & IIa & 3 \\
\hline 4 & female & 88 & 138.0 & 36.6 & A2 & I & 1 \\
\hline 5 & female & 87 & 129.0 & 42.9 & $\mathrm{~J} 2$ & IIIa & 3 \\
\hline 6 & female & 86 & 139.0 & 42.0 & A2 & $\mathrm{IIb}$ & 3 \\
\hline 7 & male & 81 & 165.0 & 74.9 & $\mathrm{~A} 1$ & I & 2 \\
\hline 8 & female & 82 & 157.0 & 54.6 & B2 & IIb & 3 \\
\hline 9 & female & 86 & 143.2 & 37.8 & $\mathrm{~J} 2$ & IIb & 2 \\
\hline 10 & female & 84 & 135.0 & 29.9 & A2 & IIa & 3 \\
\hline \multicolumn{2}{|c|}{ average } & 82.4 & 145.2 & 44.9 & & & 2.5 \\
\hline \multicolumn{2}{|c|}{ SD } & 5.6 & 11.6 & 12.7 & & & 0.7 \\
\hline
\end{tabular}

z: Ministry of Health, Labor and Welfare, Japan (J indicates self-reliance, A indicates bedridden, and B indicates bedridden). y: Ministry of Health, Labor and Welfare, Japan (independence degree of daily living for the demented elderly, I indicates independence in daily life, II indicates that it interferes with daily life, and III indicates that it interferes with daily life. $x$ : Ministry of Health, Labor and Welfare, Japan (between 1 and 5 based on assessment of care requirements). 


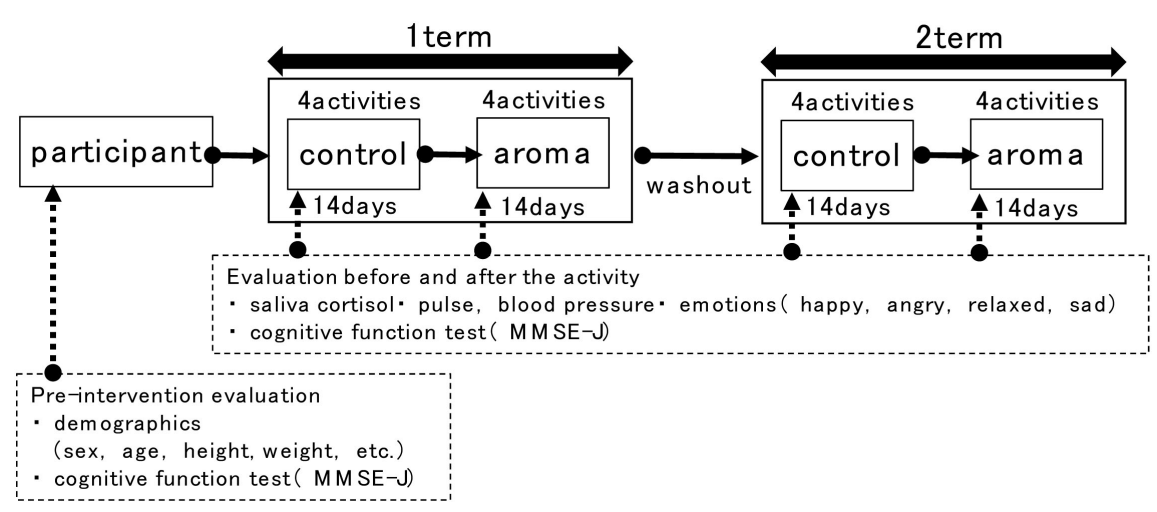

Figure 1. Flowchart of evaluations.

washout period was provided after the end of the first aroma period and before the start of the second control period to eliminate the carry-over effect during the aroma period [10]. During the control period, only Furnas oil was applied over the shoulder as a placebo.

During each period, recreational activities were carried out twice a week (origami for the first and third times, coloring for the second and fourth times), and the activities during the control period and the aroma period were the same.

\subsection{Essential Oils Used and Intervention Methods}

The essential oil of Lindera lancea, Kadono Corporation Hyogo, Japan, was used for this study. The plants collected on June 30, 2019 were extracted by steam distillation on the day of collection.

The qualitative analysis of the essential oil was performed using a Gas chromatography-mass spectrometry (GC-MS, Shimadzu Corporation, Kyoto Japan, QP-2010 Ultra) equipped with DB-5MS Ultra Inert column $(30 \mathrm{~m} \times 0.25 \mathrm{~mm}$ id, $0.25 \mu \mathrm{m}$ film thickness; Agilent Technologies, Inc., Santa Clara, CA, USA). From the essential oil analysis, 34 compounds were identified by comparing mass spectra with those in the library data (NIST14 and FFNSC3). Carvone (23.9\%), Linalool (18.2\%), Limonene (12.2\%), cis-Dihydrocarvone (8.1\%), Eucalyptol (7.6\%) and trans-Dihydrocarvone (5.1\%) was extracted as high-content components.

The blended oil obtained by diluting this essential oil with furnas oil to $1 \%$ was used for aromatherapy. The dilution concentration was set to $1 \%$ with reference to the standard of use for the elderly by the Japan Aroma Environment Association. Furnas oil is the carrier oil derived from coconut oil and is a saturated fatty acid that is difficult to oxidize. In addition, because the size of the molecule is extremely small, it penetrates deep into the skin, but it is eventually decomposed into water and carbon dioxide in the liver, so it hardly accumulates within the body [11].

For the intervention, a fragrance bath with a diffuser is common, but as a method of keeping the exposure amount of the fragrance component constant and allowing more active ingredients to be absorbed through the body, aromathera- 
py by application to the shoulder was adopted. About $1 \mathrm{ml}$ of both Furnas oil and Lindera lancea blend oil was applied to the shoulders three times by the caregiver's procedure. The time of work to apply on the shoulder was 2:00 pm.

\subsection{Evaluation Methods}

To evaluate the effects of aromatherapy intervention, we investigated 1) the degree of stress; 2) the degree of cognitive function; 3) vital signs (pulse, diastolic blood pressure, systolic blood pressure); and 4) emotional changes.

\subsubsection{Degree of Stress}

To evaluate the degree of stress, salivary cortisol concentration was investigated as an index. Cortisol is a hormone secreted from the adrenal cortex and is one of the main glucocorticoids. It is involved in stress, and when it is overstressed, the amount of cortisol secreted increases, and the reactions were sensitive. Therefore, it was called a stress hormone too.

Cortisol levels are known to fluctuate with collection time [12], and the client's saliva was collected at 2:00 pm on the first day of each test period and immediately after the activity was completed. Saliva was collected using a collection kit (Saliva Collection Aid + Cryovial, Yanaihara Institute Inc. Shizuoka, Japan), and after collection, it was immediately stored a $-4^{\circ} \mathrm{C}$ or lower and usedfor analysis.

The analysis was performed using the EIA kit (Cortisol (Sakiva) EIA Kit, Yanaihara Institute Inc. Shizuoka, Japan). The saliva sample was centrifuged at $3000 \mathrm{rpm}$ for 10 minutes and then subjected to EIA measurement [13].

\subsubsection{Degree of Cognitive Function}

To evaluate the degree of cognitive function, we used MMSE-J (Nihon Bunka Kagakusha Corporation Tokyo, Japan.2006.), which is the Japanese version of MMSE (Mini-Mental State Examinaton; Folstein, Folstein, and McHugh, 1975). We investigated the cognitive function of the clients. The cognitive function survey has conducted a total of 5 times before the intervention, after the end of the first control period, after the end of the second aroma period, before the start of the second control period, and after the end of the second aroma period. The evaluation was made by three people: a nurse, a caregiver, and a life supporter.

\subsubsection{Vital Signs (Pulse, Systolic Blood Pressure, Diastolic Blood Pressure)}

As vital signs, pulse, systolic blood pressure, and diastolic blood pressure were measured before and after recreational activities performed during each test period. An upper arm sphygmomanometer (HCR-7601T, OMRON Corporation Kyoto, Japan) was used for the measurement.

\subsubsection{Emotional Changes}

A wristband-type wearable device (SilmeeTMW20, TDK Corporation Tokyo, Japan) was worn on the client's left wrist to investigate emotional changes. The size of the device is small $(20.5 \times 65.0 \times 12.5 \mathrm{~mm}, 29.5 \mathrm{~g})$, and it is difficult for 
the client to be invasive. The device extracts two emotional indexes, Arousal and Valence, as emotional data every 5 seconds, and plots them in Cartesian coordinates to classify them into four types of emotions: Happy, Angry, Relaxed, and Sad. Measurements of emotional changes were performed during recreational activities conducted during each test period.

\subsubsection{Statistical Analysis}

This study was conducted as a single-blind, single-case study. The intervention period was a total of four periods, two control periods and an aroma period, but the analysis other than the cognitive function survey was basically divided into the first and second times for comparison.

For the cognitive function survey, multiple comparisons (Steel-Dwass method) were performed 5 times from before the intervention at the end of all interventions, and for stress and vital signs, the difference before and after the activity during each intervention period. The Wilcoxon signed-rank sum test was performed for emotions, and the Wilcoxon signed-rank sum test was performed on the difference between the control period and the aroma period during each intervention period $(\mathrm{p}<0.05)$. For statistical processing, statistical software Excel Statistics 7.0 for Windows (Esumi Corporation Tokyo, Japan, 2019 versions) was used.

\subsubsection{Research Ethics}

As an ethical consideration, the director of the research facility and the clients and their families (substitutes) were fully explained in writing and verbally about the purpose of this study and the survey items.

We strictly observed the Helsinki Declaration of 2015 (revised in 2013), explained the purpose and outline of this study to them and obtained informed consent from them beforehand. In addition to these, UMIN registration was performed during clinical research (UMIN000041961).

The approval of the 135th Clinical Trial Ethics Review Committee of Kyushu University was obtained for the implementation of this study (20202006).

\section{Results}

\subsection{Salivary Cortisol Concentration}

Figure 2 shows changes in salivary cortisol concentration before and after recreational activities. There was no significant difference between the control period and the aroma period before and after the recreational activity in both the first and second intervention periods. Looking at the mean \pm standard deviation, the first intervention showed an $11 \%$ decrease from $0.19 \pm 0.09 \mu \mathrm{g} / \mathrm{dL}$ before activity to $0.17 \pm 0.08 \mu \mathrm{g} / \mathrm{dL}$ after activity during the control period. The aroma period decreased by $6 \%$ from $0.16 \pm 0.08 \mu \mathrm{g} / \mathrm{dL}$ before the activity to $0.15 \pm 0.07 \mu \mathrm{g} / \mathrm{dL}$.

Looking at the second intervention period, there was a $43 \%$ increase from 0.21 $\pm 0.13 \mu \mathrm{g} / \mathrm{dL}$ before the activity to $0.30 \pm 0.33 \mu \mathrm{g} / \mathrm{dL}$ after the activity during the control period. On the other hand, before the activity during the aroma period, 


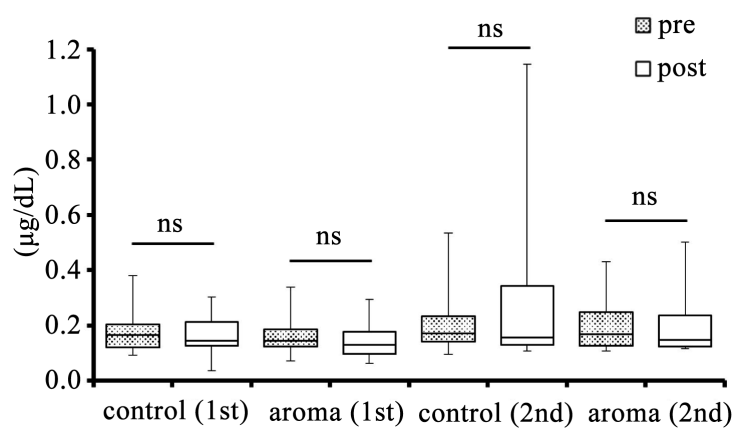

Figure 2. Procedure for determining salivary cortisol secretion. ns shows that there is no significant difference before and after recreational activities by Wilcoxon signed-rank sum test.

it increased from $0.20 \pm 0.10 \mu \mathrm{g} / \mathrm{dL}$ to $0.20 \pm 0.12 \mu \mathrm{g} / \mathrm{dL}$ after the activity, but the rate of increase was $3 \%$, which was almost the same.

\subsection{Cognitive Function}

The results of cognitive function (MMSE-J) are shown in Figure 3. There were no significant differences from pre-intervention over all study periods. The mean \pm standard deviation was $14.8 \pm 7.0$ points before the intervention, $15.1 \pm$ 7.8 points after the end of the first control period, and $15.0 \pm 8.3$ points after the end of the first aroma period, showing almost no change. However, 12 days after the end of the aroma period, the score increased to $18.3 \pm 8.0$ points. After the end of the second control period, it decreased by about 3 points to $15.4 \pm 7.4$ points. However, after the end of the second aroma period, it was $16.5 \pm 8.6$ points, an increase of about 1.0 point, and finally it increased by about 1.7 points from before the intervention.

\subsection{Vital Signs}

Figure 4 shows the change in pulse rate before and after the activity for each intervention period. In each intervention period, there was no significant change in pulse rate before and after the activity in both the control period and the aroma period. The mean $\pm \mathrm{SD}$ showed that the intervention period, and the test section were generally between 70 and 80 times/min.

As vital signs for each intervention period, changes in systolic blood pressure before and after activity are shown in Figure 5 . The first intervention period was not significantly different from the control period. The second aroma period was $132.7 \pm 14.4 \mathrm{mmHG}$ to $107.5 \pm 15.2 \mathrm{mmHG}$, and the fourth was $130.6 \pm 13.9$ mmHG to $112.6 \pm 18.1 \mathrm{mmHG}$, showing a significant decrease in systolic blood pressure after activity $(\mathrm{p}<0.05)$.

During the second intervention period, there was a significant decrease in systolic blood pressure after the second activity during the control period and after the non-second activity during the aroma period $(\mathrm{p}<0.05)$. Systolic blood pressure tended to decrease after activity, regardless of the intervention period or study interval, but the aroma period was more pronounced. 


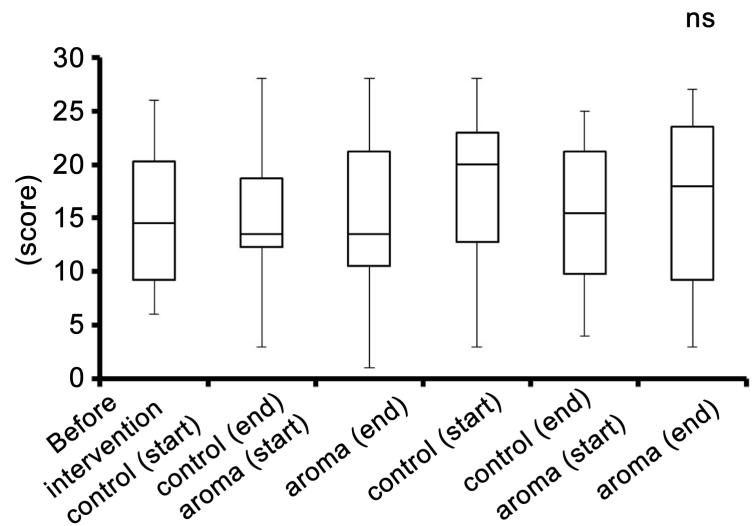

Figure 3. Transition of cognitive function. ns shows that there is no significant difference between pre-intervention and study duration by multiple comparisons (Steel-Dwass method).

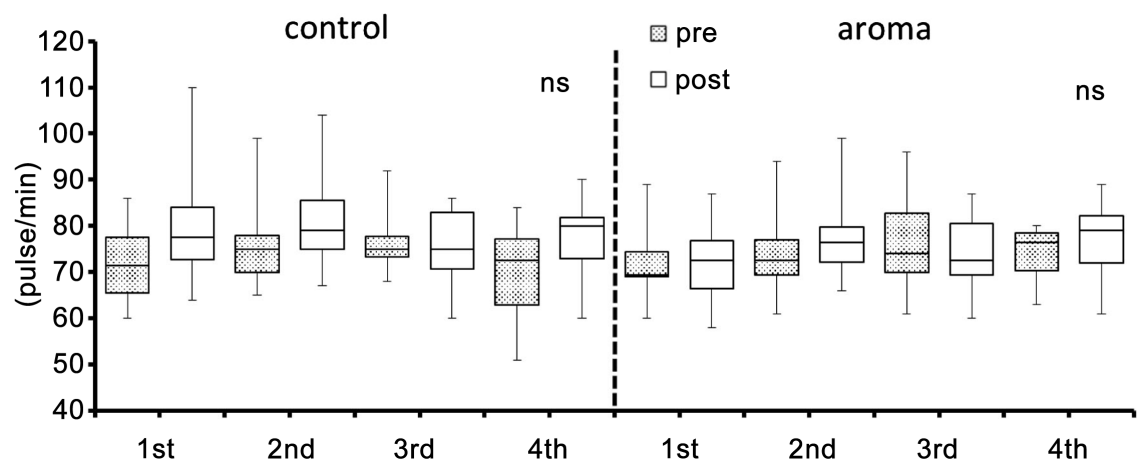

(a)

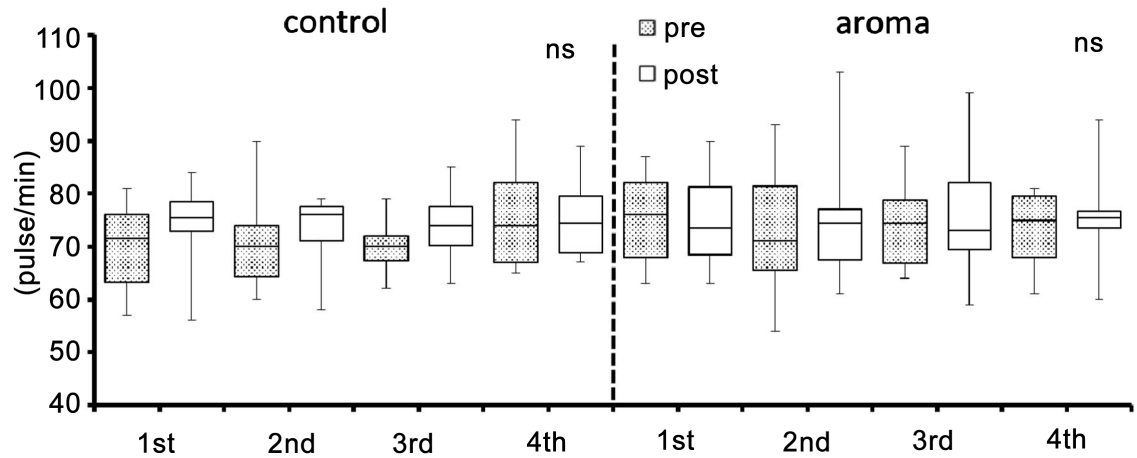

(b)

Figure 4. Changes in pulse rate. (a) First intervention period; (b) Second intervention period. ns shows that there is no significant difference before and after the activity by Wilcoxon signed-rank sum test.

Subsequently, Figure 6 shows the changes in diastolic blood pressure before and after the activity for each intervention period. During the first intervention period, there was no significant difference between before and after the activity in the control period. The second aroma period was $68.9 \pm 9.6 \mathrm{mmHG}$ to $59.7 \pm$ $7.0 \mathrm{mmHG}$, and the fourth was $67.0 \pm 9.4 \mathrm{mmHG}$ to $61.1 \pm 7.7 \mathrm{mmHG}$, showing a significant decrease in systolic blood pressure after activity $(\mathrm{p}<0.05)$. 


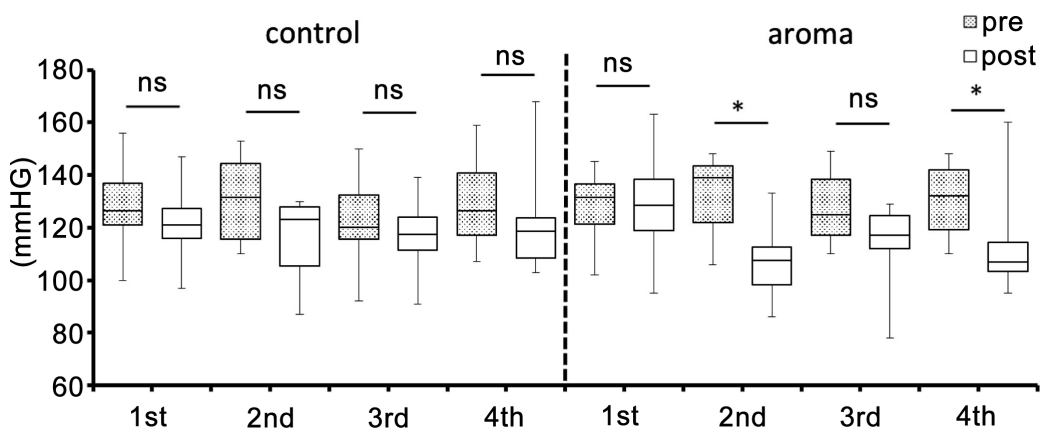

(a)

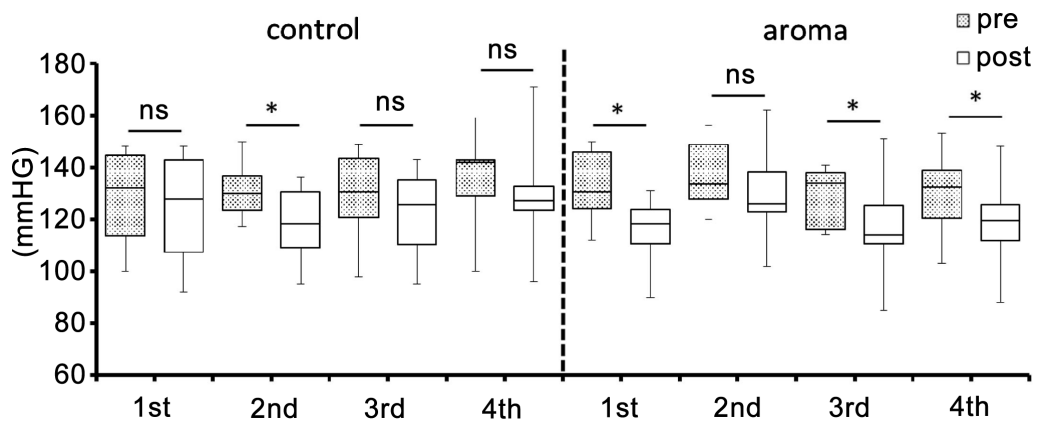

(b)

Figure 5. Transition of systolic blood pressure. (a) First intervention period; (b) Second intervention period. ns shows that there is no significant difference before and after the activity by Wilcoxon signed-rank sum test. ${ }^{\star}$ Is significantly different at the $5 \%$ level.

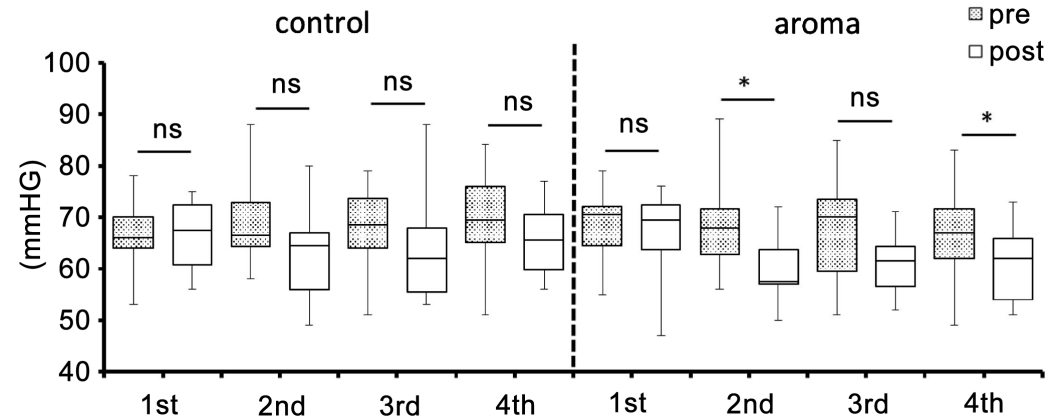

(a)

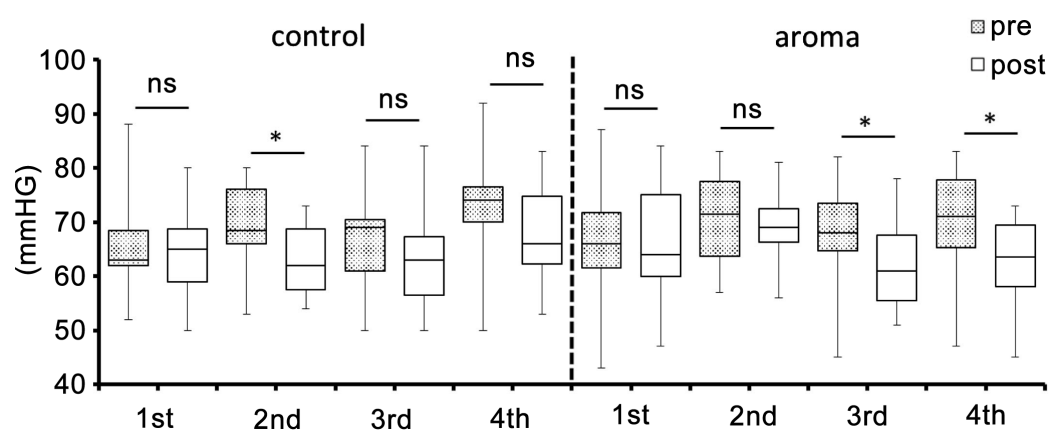

(b)

Figure 6. Changes in diastolic blood pressure. (a) First intervention period; (b) Second intervention period. ns shows that there is no significant difference before and after the activity by Wilcoxon signed-rank sum test. ${ }^{*}$ is significantly different at the $5 \%$ level. 
During the second intervention period, there was a significant decrease in systolic blood pressure after the second activity during the control period and after the third and fourth activities during the aroma period $(\mathrm{p}<0.05)$. The number of activity times that showed a significant difference was about 70 mmHG before the activity, but after the activity it decreased to about $60 \mathrm{mmHG}$ by about $10 \mathrm{mmHG}$.

From these facts, it was found that aromatherapy using essential oil of Lindera lancea tends to lower blood pressure in systole and diastole.

\subsection{Emotional Changes}

Figure 7 shows the changes in emotions during an activity during each intervention period. For the emotion analysis, the ratio of 4 emotions of the clients recorded every 5 seconds during the activity was calculated, and the average value of 10 clients was graphed. Multiple comparisons were made for each emotion in each session, but no significant difference was shown in any intervention period or test segment.

Looking at each emotion for each intervention period, the lowest value of "happy" in the first intervention period was 7\% in the first aroma period, and the highest value was $29 \%$ in the fourth control period. The lowest value of "angry" was $12 \%$ at the 4 th aroma period, and the highest value was $64 \%$ at the 1 st

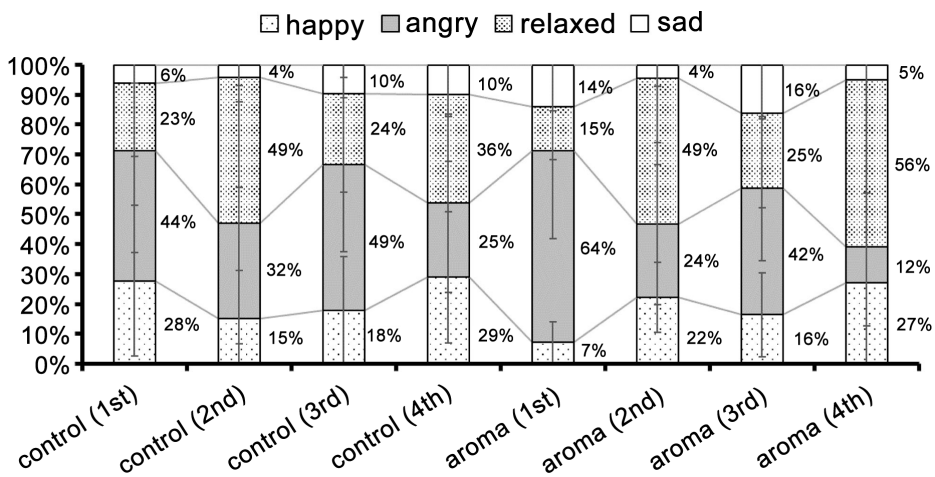

(a)

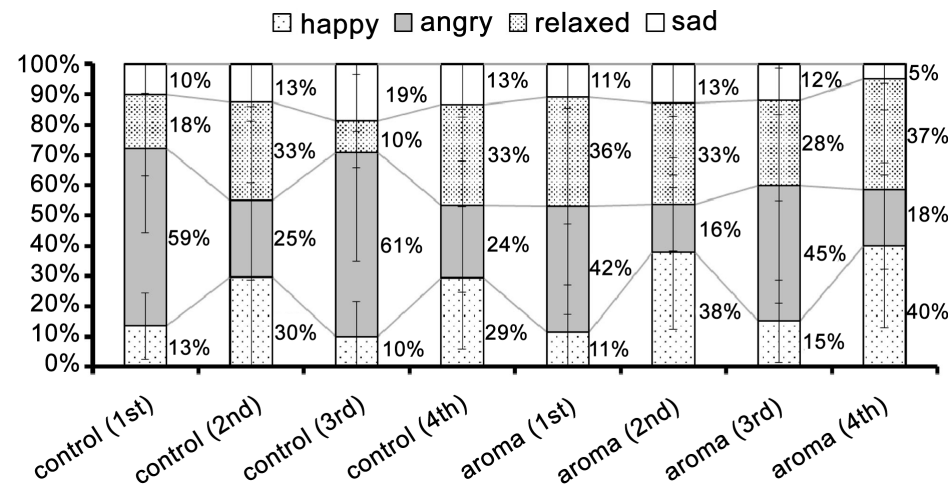

(b)

Figure 7. Transition of emotions. (a) First intervention period; (b) Second intervention period. Emotions were not significantly different in all test intervals. 
aroma period, the lowest value of "relaxed" was $15 \%$ at the 1 st aroma period, and the highest value was $56 \%$ at the 4 th aroma period. The lowest value of sad was $4 \%$ for the second control period and the second aroma period, and the highest value was $16 \%$ for the third aroma period. Regardless of the test section, the values of "angry" for the first and third activities tended to be high.

Looking at the second intervention period, the lowest value of "happy" was $10 \%$ at the third control period, and the highest value was $40 \%$ at the fourth aroma period. The lowest value of angry was $16 \%$ for the second aroma period, and the highest value was $61 \%$ for the third control period. The lowest value of relaxed was $10 \%$ at the third control period, and the highest value was $37 \%$ at the fourth aroma period. The lowest value of sad was $5 \%$ at the 4 th aroma period, and the highest value was $19 \%$ at the 3 rd control period.

In the second intervention period as well as in the first activity, the value of angry in the first and third activities tended to be higher, but the relaxed value was about $30 \%$ in all activity periods during the aroma period.

\section{Discussions}

There have been many studies that have verified the stress-reducing effect of aromatherapy using various essential oils. For example, changes in salivary cortisol by aroma massage with a mixed oil of lavender and geranium in healthy clients [14] and verification of salivary amylase activity by an aromatic bath using chamomile in healthy university students [15], etc., but none of them showed a significant effect of reducing stress by aroma intervention.

In this study as well, there was no significant difference between the intervention period and the test interval, but the aromatherapy intervention reduced the post-active salivary cortisol concentration during the first intervention period. During the second intervention period, the concentration increased in both groups, but the rate than the increase was lower in the aromatherapy intervention group than in the control period, indicating that stress could be reduced (Figure 2).

On the other hand, the reason why the cortisol concentration did not decrease significantly was that the recreation performed at the time of collection was "origami", and the proportion of angry was high in the emotional analysis (Figure 7). It is possible that the activity was highly stressful for the person. In the future, it will be necessary to verify by changing the content of recreation.

Changes in cognitive function were not significantly different from all surveys compared to before the intervention but were highest after the end of the first intervention period and immediately after the 12-day washout period. Finally, after the end of the aroma period of the second intervention period, an improvement of 1.7 points was observed compared to before the intervention (Figure 3). In a study of elderly people sprayed with rosemary camphor and lemon essential oil, and lavender and orange sweet essential oil with a diffuser, cognitive function improved in the order of control period, aroma period, and washout period [16], a similar tendency was observed during this study. 
According to previous studies, the limbic system, where the scent is transmitted, is the region where the hippocampus and amygdala are located. The mechanism has been shown to attenuate sympathetic nerve activity by aroma stimulation to the hypothalamus, enhance parasympathetic nerve activity, and reduce stress and anxiety [17]. Although this study involved biweekly interventions, longer-term interventions were considered necessary to verify cognitive function.

Looking at the pulse of vital signs, there was no significant difference between the intervention period and the test interval. It is considered that this is because the recreational activities carried out in this study were origami and coloring books, which did not involve exercise or movement, and therefore, did not impose a physical load (Figure 4). Blood pressure was significantly reduced after many activities during the aroma intervention period in both systole and diastole (Figure 5 and Figure 6).

Although the conditions are different, there was a study in which a scent such as lavender essential oil was inhaled in patients with coronary artery disease before and after percutaneous coronary angioplasty. As a result of inhalation before and after surgery, it has been reported that postoperative anxiety and resting blood pressure were significantly lower in the intervention group than in the control group [18]. Inhalation of lavender essential oil for patients with coronary artery bypass grafting has been reported to have an improving effect on systolic blood pressure 2 - 3 days after surgery [19]. Furthermore, there was a report that blood pressure was significantly reduced by percutaneous absorption of a mixed oil of bergamot oil and lavender oil, which indicated a decrease in autonomic nervous arousal [20].

As in this study, there is no case of introducing aromatherapy by Lindera lancea to elderly people requiring nursing care, but olfactory stimulation by Lindera lancea aroma stabilizes the mood and emotions of the client and suppresses the rise in blood pressure or considered to have decreased [21].

In sentiment analysis, four emotions were quantified using a wearable device. Although the effects of worker emotions on labor productivity have already been elucidated using the same device as in this study, emotional quantification by aromatherapy intervention is unprecedented. In this study, there were no significant differences in the four emotions depending on the intervention period and test section, but we were able to capture changes in emotions due to differences in recreational activities (Figure 7). In addition, among the emotions during the aroma period during the second intervention period, relaxed did not fluctuate due to differences in recreational activities, and it is considered that the client was able to spend about $30 \%$ of the activity time in a relaxed manner.

It is known that when people work, they are affected by environmental factors such as surrounding sounds, lights, and scents [22], but they utilize aromatherapy as one of the therapeutic environmental factors of occupational therapy. This can be expected to change the mood and emotions of the client, as well as the motivation to perform work, and as a result, have a positive effect on the 
client's work behavior and daily activities [21]. In this study, emotional changes are considered to be influenced in many parts by the content of recreational activities, but we selected activities that give positive emotions to the clients by quantifying emotions, and further intervened in aromatherapy. Thereby, it is thought to function as a more effective complementary alternative therapy.

Since the global pandemic began in earnest in 2021, the COVID 19 pandemic has led to restrictions on human-to-human interaction, so the importance of emotional control represented by stress control is increasing for all humankind [23] [24] [25] [26] [27]. Therefore, it was expected that this aromatherapy as complementary and alternative medicine could contribute to the good emotional control of all the people involved.

\section{Limitation}

Since this study limits aromas, it is necessary to compare them with the effects of other aroma oils. In addition, since the number of $\mathrm{N}$ subjects and the number of controls are not large, it was considered necessary to conduct research with more subjects.

\section{Acknowledgements}

We would like to express our deep gratitude to Minako Tanabe and Emi Hata, who are the facility users and staff of the A Day Service Center of the research target facility, for their cooperation in carrying out this research. We would like to thank the institution Wood Extractives Laboratory, Forestry and Forest Products Research Institute for the cooperation of GC-MS analysis. We would also like to thank Dr. Kusumoto Norihisa of the same organization for his advice on essential oils. We would also like to express our deep gratitude to Mr. Satoshi Chiba and Mr. Shinichiro Iwata of the Smart Industry Division of NEC Corporation for their advice regarding the rental and use of wearable devices.

\section{Conflicts of Interest}

The authors declare no conflicts of interest regarding the publication of this paper.

\section{References}

[1] Alzheimer's Disease International (2015) World Alzheimer Report 2015. 10-45. https://www.alzint.org/u/worldalzheimerreport2015summary.pdf

[2] Forrester, L.T., Maayan, N., Orrell, M., Spector, A.E., Buchan, L.D. and Soares-Weiser, K. (2014) Aromatherapy for Dementia. Cochrane Database of Systematic Reviews, 1-56. https://doi.org/10.1002/14651858.CD003150.pub2

[3] Kimura, Y., Tsunawaki, S., Taniguchi, M., Saito, J., Kitaura, M., Hosoda, R., Yonehara, A., Hasegawa, J., Kojima, N., Shimizu, Y., Morimoto, Y., Yorita, T., Ojima, R. and Urakami, K. (2005) Effect of Aromatherapy on Patients with Alzheimer's Disease. Dementia Japan, 19, 77-85. http://dementia.umin.jp/19-1-77-85.pdf

[4] Quynh-anh, N. and Carol, P. (2007) The Use of Aromatherapy to Treat Behavioural 
Problems in Dementia. International Journal of Geriatric Psychiatry, 23, 337-346. https://doi.org/10.1002/gps.1886

[5] Walker, M.P., Ayre, G.A., Cummings, J.L., Wesnes, K., McKeith, I.G., O’Brien, J.T. and Ballard, C.G. (2000) Quantifying Fluctuation in Dementia with Lewy Bodies, Alzheimer's Disease, and Vascular Dementia. Neurology, 54, 1616-1625. https://doi.org/10.1212/WNL.54.8.1616

[6] Harris, P. and Rees, R. (2000) The Prevalence of Complementary and Alternative Medicine Use among the General Population: A Systematic Review of the Literature. Complementary Therapies in Medicine, 8, 88-96. https://doi.org/10.1054/ctim.2000.0353

[7] Buckle, J. (2003) Clinical Aromatherapy: Essential Oils in Practice. 2nd Edition, Elsevier, London, UK.

[8] OnHealth Network Company (2000) Alternative Practices. https://www.crunchbase.com/organization/onhealth-network-company

[9] Moss, M., Cook, J., Wesnes, K. and Duckett, P. (2003) Aromas of Rosemary and Lavender Essential Oils Differentially Affect Cognition and Mood in Healthy Adults. International Journal of Neuroscience, 113, 15-38. https://doi.org/10.1080/00207450390161903

[10] Chinen, S., Kanetake, N., Fukuhara, A., Kamiya, H., Miyamori, T., Toyosato, T. and Yokota, T. (2012) Study on the Effect of Aromatherapy on Activities of Daily Living, Cognitive Function, and Behavioral and Psychological Symptoms among the Elderly with Dementia. Ryukyu Medical Journal, 31, 41-49.

http://hdl.handle.net/20.500.12001/11661

[11] Mikami, K. (2007) NARD Chemotype Essential Oil Dictionary Ver, 6. NARD JAPAN, Tokyo, 136-138. https://www.nardjapan.gr.jp/publishment

[12] Knutsson, U., Dahlgren, J., Marcus, C., Rosberg, S., Bronnegard, M., Stierna, P. and Albertsson-Wikland, K. (1997) Circadian Cortisol Rhythms in Healthy Boys and Girls: Relationship with Age, Growth, Body Composition, and Pubertal Development. The Journal of Clinical Endocrinology \& Metabolism, 82, 536-540.

[13] Iwasa, Y., Muramatsu, Y., Aoki, H., Tomiyama, C., Saito, T., Nishikata, M. and Uchiyama, M. (2017) Sleep and Stress of Late Middle Age Males Who Are Forced to Live in Emergency Temporary Houses and Post-Earthquake Public Houses for a Long Period Due to the Fukushima Daiichi Nuclear Power Station Accident. Health, 9, 1787-1800. https://doi.org/10.4236/health.2017.913130

[14] Wu, J.J., Cui, Y., Yoon-Sil, Y., Moon-Seok, K., Sung-Cherl, J., Park, H.K., Hye-Young, Y., Jang, W.J., Lee, S., Kwak, Y.S. and Su-Yong, E. (2014) Modulatory Effects of Aromatherapy Massage Intervention on Electroencephalogram, Psychological Assessments, Salivary Cortisol and Plasma Brain-Derived Neurotrophic Factor. Complementary Therapies in Medicine, 22, 456-462. https://doi.org/10.1016/j.ctim.2014.04.001

[15] Tanaka, M. and Koura, S. (2012) Effects of Chamomile Aroma on Salivary Amylase Activity and EEG under Mental Workload. Journal of Kyushu Univ. of Health and Welfare, 13, 71-76. https://core.ac.uk/download/pdf/52204118.pdf

[16] Jinbo, D. and Urakami, K. (2008) Effect of Aromatherapy on Patients with Severe Alzheimer's Disease. Journal of Japanese Society of Aromatherapy, 7, 43-48.

[17] Noda, A., Miyazaki, S. and Urakami, K. (2018) Expectations for Aromatherapy to Improve Sleep and Cognitive Function. Bulletin of Health Culture Promotion Foundation, 42-48. https://kenkobunka.com/kenbun/kb53/noda53.pdf

[18] Mi-Yeon, C., Min, E.S., Myung-Haeng, H. and Lee, M.S. (2013) Effects of Aroma- 
therapy on the Anxiety, Vital Signs, and Sleep Quality of Percutaneous Coronary Intervention Patients in Intensive Care Units. Evidence-Based Complementary and Alternative Medicine, 2013, Article ID: 381381.

https://doi.org/10.1155/2013/381381

[19] Bikmoradi, A., Seifi, Z., Poorolajal, J., Araghchian, M., Safiaryan, R. and Oshvandi, K. (2015) Effect of Inhalation Aromatherapy with Lavender Essential Oil on Stress and Vital Signs in Patients Undergoing Coronary Artery Bypass Surgery: A Single-Blinded Randomized Clinical Trial. Complementary Therapies in Medicine, 23, 331-338. https://doi.org/10.1016/j.ctim.2014.12.001

[20] Hongratanaworakit, T., Heuberger, E. and Buchbauer, G. (2003) A Screening Test for Efficacy of Aroma in Humans. Proceedings of the 51 st Annual Congress of the Society for Medical Plant Research (51 st GA), 4, 209.

[21] Iokawa, K. (2018) Utilization of Aromatherapy in Occupational Therapy. The Japanese Journal of Rehabilitation Medicine, 55, 984-988.

https://doi.org/10.2490/jjrmc.55.984

[22] Kadoya, Y., Khan, M. S. R., Watanapongvanich, S. and Binnagan, P. (2020) Emotional Status and Productivity: Evidence from the Special Economic Zone in Laos. Sustainability, 12, 1544. https://doi.org/10.3390/su12041544

[23] Padilla, R. (2011) Effectiveness of Environment-Based Interventions for People with Alzheimer's Disease and Related Dementias. American Journal of Occupational Therapy, 65, 514-522. https://doi.org/10.5014/ajot.2011.002600

[24] Yamada, M., Kimura, Y., Ishiyama, D., et al. (2020) Effect of the COVID-19 Epidemic on Physical Activity in Community-Dwelling Older Adults in Japan: A Cross-Sectional Online Survey. The Journal of Nutrition, Health \& Aging, 24, 948-950. https://link.springer.com/article/10.1007/s12603-020-1501-6 https://doi.org/10.1007/s12603-020-1424-2

[25] Japan Society for Dementia Prevention (2020) Related to New Coronavirus Infection. Questionnaire Total Result. http://ninchishou.jp/publics/index/150/Downloads/202010081419406792\%20(1).pdf

[26] WHO (2020) Coronavirus Disease 2019 (COVID-19) Situation Report 43. https://www.who.int/docs/default-source/coronaviruse/situation-reports/20200303sitrep-43-covid-19.pdf?sfvrsn=2c21c09c_2

[27] Armitage, R. and Nellums, L.B. (2020) COVID-19 and the Consequences of Isolating the Elderly. Lancet Public Health, 5, e256.

https://doi.org/10.1016/S2468-2667(20)30061-X 